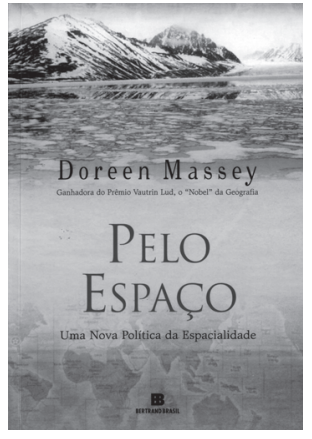

\section{Doreen Massey. Pelo Espaço. Uma Nova politica da espacialidades}

\author{
Rio de Janeiro: Editora Bertrand Brasil Ltda., 2008, 312 p.
}

El texto se compone de cinco partes $y$ quince capítulos, distribuidos inequitativamente. A través de ellos, la autora desarrolla un sinnúmero de tesis que participan en el seguimiento del objeto de estudio de la geografía. Un hecho relevado tanto por Massey como por los traductores (Hilda Pareto Maciel y Rogério Haesbaert) es el uso de palabras inventadas que pretenden clarificar conceptos o transmitir experiencias a quien se aproxima a las temáticas epistemológicas aquí contenidas.

Doreen Elizabeth Massey (1938), académica de la Open University, Inglaterra, fue honrada con el Premio Nobel de Geografía, el Premio Vautrin Lud, el año 1998. Su trabajo abarca la mayor parte de las preocupaciones de la geografía humana, siendo reconocida como una de las especialistas más importantes en materias tales como género, teoría geográfica, geografía urbana, globalización y desarrollo. Su obra está anidada fundamentalmente en la crítica althusseriana, especialmente en el reconocimiento de que las clases sociales tendrían algún nivel de autonomía relativa en el tramado social, planteamiento que la distancia de la escuela económica marxista pura y la aproxima al estructuralismo y al posestructuralismo. Para una mayor comprensión de sus orígenes se recomienda la lectura del capítulo tres de Pelo Espaço. Massey reitera algo que ha planteado previamente, su dedicación al estudio del problema del espacio geográfico, que es el objeto que otorga contenido a esta

1 Instituto de Geografía, Pontificia Universidad Católica de Chile (Chile). E-mail: apaulsen@uc.cl obra, la que se analizará con algún nivel de detalle a continuación.

La Primera Parte, Establecendo o cenário, detalla tres consideraciones que alertan acerca de la mirada desde la cual la científica se aproxima a la realidad. En la primera de estas, Massey plantea como hipótesis que el modo como imaginamos el espacio tiene efectos específicos en los individuos y en las colectividades, lo cual representa en los eventos asociados a la conquista de Tenochtitlán por las fuerzas dirigidas por Hernán Cortés; el altivo conquistador percibe el espacio como una superficie propia, continua y probablemente infinita, donde lo que se encuentra al avanzar sobre sus rugosidades o superando las discontinuidades (mar, tierra, por ejemplo) es un fenómeno que está allí para ser usado y apropiado en tanto son parte de una historia, la cual se superpone a aquella que otros (representados por los aztecas) producen, y que más que dinamizarlos convirtiéndolos en sujetos, los sitúa en una postura pasiva, lo cual es probablemente el primer disparo desde el cual se impondrán los términos de la conquista. Massey relaciona esta dinámica (no olvidar su raigambre estructuralista) con los eventos contemporáneos relacionados con el capital global. "É uma cosmologia impensável, para usar o termo mais brando, mas leva consigo efeitos sociais e 'políticos. Portanto, esse modo de conceber o espaço pode assim, facilmente, nos levar a conceber outros lugares, povos, culturas simplesmente como um fenômeno "sobre" essa superfície. Não é uma manobra inocente; desta forma, eles ficam desprovidos de história. Imobilizados, esperam a chegada de Cortés (ou a nossa, ou a do capital global). 
"Lá estão eles, no espaço, no lugar, sem suas próprias trajetórias" (Massey, 2008: 23).

El conquistador, independientemente del tiempo en el cual ejecute su acción, imagina el espacio como superficie, continuidad, donde no hay lugar para el encuentro y para el diálogo en una extensión donde una mentalidad ejecuta una única historia.

En la segunda consideración, la autora critica la visión sostenida por Estados Unidos y el Reino Unido acerca de la inevitabilidad de la globalización. Advierte acerca de los peligros que esta postura conlleva, esto es, la imposición de una sola trayectoria que barre con la multiplicidad y con la posibilidad de futuros alternativos y que, además, transforma al espacio en tiempo y a la geografía en historia. Se reconoce en esta postura un elemento más del proceso de conquista reseñado anteriormente. Por otra parte, aconseja considerar a la globalización como un proyecto, una de muchas (posibles) narrativas que distrae grandes energías para imponerse, y como tal, susceptible de ser confrontado con otros que podemos imaginar y que otorgue a las colectividades la posibilidad de construir historias propias que sean coherentes con sus propias herramientas y recursos. "Conhecemos o contra-argumento: a "globalização" em sua forma atual não é o resultado de uma lei da natureza... é um projeto... Essa não é uma descrição do mundo como ele é, mas uma imagem através da qual o mundo está sendo feito" (Massey, 2008: 24).

La tercera consideración defiende la vitalidad en los tiempos económicos del lugar. Este concepto de gran valor simbólico puede ser aplicado con diferentes matices, pero siempre conserva una connotación de acopio, riqueza y protección, entre otros. Massey desafía a reflexionar acerca de la artificial separación que hacemos entre espacio (geográfico) y lugar, por cuanto se rechaza: "... essa distinção, por mais sedutora que pareça, entre lugar (como sentido, vivido e cotidiano) e espaço (como o quê? o exterior? o abstrato? o sem significação?)" (Massey, 2008: 25).

Por cuanto los atributos positivos que parece poseer el lugar también los presenta el espacio geográfico; asumir que el espacio geográfico no es cotidiano, íntimo ni personal ha dado fuerza a la conceptualización de lugar. Dicho de otro modo, a partir de una falacia se origina un concepto que ha marcado el desarrollo de algunas corrientes de la geografía humana durante el siglo XX.

Desde estas constataciones se desarrolla el capítulo titulado Proposições iniciais; quienquiera avanzar en el conocimiento de planteamientos heterodoxos acerca del espacio geográfico y se incline por sistematizaciones que develan al hombre (y no a modelos del accionar humano) tal y como interviene, disfrutará en mayor medida los contenidos de este apartado. Massey comienza a reflexionar, situando su teoría a partir de hipótesis de trabajo que abordan al espacio como un producto social gestado en sociedad, en interrelaciones y en la convivencia (coexistencia) de los diversos (y heterogéneos) actores sociales que siempre actúan y actuarán en función de sus propios intereses y propensiones.

En este análisis la autora avanza desde posturas estructuralistas (que posteriormente acusará como productora de un problemático imaginario que sindica al espacio como inmóvil, cerrado y estático) y posestructuralistas esencialistas (donde espacio es lo contrario al tiempo cronológico) hacia modelos relacionales acerca del rol y evolución del tiempo cronológico en eventos geográficos, lo cual se expresa en el tratamiento de temas tales como diferencia, trayectoria, historia, pluralidad, movimiento deconstructivo de espaciamiento, temporalidad, modelamiento (o modelaje) cultural, encanto espacial, dislocation o desarticulización, continuidad, movimiento.

La segunda parte, Associações pouco promissórias, nos entrega antecedentes acerca de lo que Massey define como "imaginarios" (o imaginaciones) espaciales entendidas como grandes ideas fuerzas que condicionan las opiniones acerca del espacio y que terminan por conculcar la posibilidad de realizar descubrimientos acerca de otras facetas $y / 0$ propiedades inherentes a objeto de estudio de la geografía; dicho de otro modo, el apego a enfoques tradicionales acerca del espacio geográfico genera in- 
movilismo y priva de conocer otros aspectos de su naturaleza y espesor, reduciendo los análisis a posturas filosóficas (nunca geográficas dado que la preocupación por el tiempo ha inhibido la posible reflexión acerca del espacio) debilitadoras que dirigen la discusión hacia corrientes significadoras ya exploradas y no hacia nuevas líneas de pensamiento.

La reflexión se organiza en función de los postulados de Henri Bergson; esta y otras filosofías son analizadas como plataformas o recuentos desde los cuales podemos seguir la evolución de una discusión (que aún no se agota) ya centenaria. El capítulo Espaço/ representação, integra y compara a Bergson, Deleuze, Laclau, Soja, De Certau, entre otros, en función del análisis de la crisis de la espacialidad y la invisibilización del espacio en beneficio del tiempo. Se recomienda apoyar la lectura de esta porción del texto con los contenidos de The production of space de Henri Lefevbre y Time and free will de Henri Bergson, sobre todo para comprender las claves analíticas desde las cuales se sustenta la discusión acerca de las relaciones entre las representaciones acerca del espacio como representación y en abstracto. La comprensión de un tema tan complejo es apoyada por la selección de un adecuado y pertinente staff de alusiones bibliográficas que sitúan a la filosofía como un campo promisorio de ejemplos que abordan la evolución del proceso de superposición del tiempo por sobre las consideraciones referidas al espacio en gran parte de la tradición occidental del siglo pasado que afectó al desarrollo de la epistemología geográfica, especialmente en el escenario anglosajón.

El capítulo titulado A morada - prisão da sincronia, requiere para su comprensión de un repaso de los fundamentos de las corrientes estructuralistas en materia de la concepción de realidad y las formas como esta puede ser analizada. Además, se precisa seguir una gran variedad de argumentaciones que pretenden ayudar a resolver la problemática del tiempo como ente (¿o sujeto?) modificador del espacio. Massey señala que: "Os estruturalistas argumentavam contra o domínio da narratividade, que era interpretada como temporalidade (diacronia etc., etc.). Em sua avidez ao fazer isso (ma- nifestar - se contra um presumido domínio da temporalidade) equiparam suas estruturas atemporais como espaço. Se essas estruturas não fossem atemporais, teriam de ser espaciais. Estrutura e processo eram interpretados como espaço e tempo. O espaço era concebido (ou tal vez este verbo seja demasiado forte - era simplesmente suposto) como a absoluta negação do tempo" (Massey, 2008: 65).

Desde esta perspectiva se presentan las debilidades del enfoque estructuralista, especialmente en lo que dice relación con el tratamiento de la sincronía, problema advertido en los abordajes de Soja, Osborne, Lévi-Strauss, Lechte, Althusser, entre otros. Se propone la superación del enfoque estructuralista mediante el recurso posestructuralista como un modo de movilizar aqueIlo que de suyo es móvil, dinámico y cambiante. Es indispensable señalar que la mayor parte de las consideraciones que se vierten en la obra de Massey distancian a la autora de la inmovilidad y estancamiento propio de dicha corriente en pos de consideraciones más empíricas y pragmáticas que aborden al espacio en su dimensión sincrónica y diacrónica. ¿Por qué sacrificar aquello que es propio del objeto de la geografía (un espacio siempre dinámico a consecuencia del obrar humano) en pos de una sistematización que termina por desfigurarlo en algo que nunca es, fue o será?

El capítulo, As horizontalidades da desconstrução, continúa la reflexión previa y pretende mostrar mecanismos o dispositivos de superación de las ficciones inmovilistas propias del estructuralismo y, en alguna medida, también del posestructuralismo. Se recurre al enfoque derridaniano como punto de partida desde el cual evolucionan argumentos, tesis, comparaciones y posturas cuyo eje parece ser el tratamiento mediante el método de la desconstrucción de la dialéctica espacio-espacialización donde esta acción (la espacialización) es textualización y diferenciación, tal como la definen y comprenden Foucault y Derrida, entre otros. A partir del análisis de la dialéctica ya consignada se abordan problemas referidos a la horizontalidad del espacio, su posible interpretación, los procesos de diferenciación-diferimento espacio-temporal, multiplicidad 
(de los elementos que constituyen tanto al espacio como a la espacialización), deslocación. Un geógrafo interesado en el cultivo de las corrientes fenomenológicas, humanísticas o radicales, disfrutará la lectura de este interesante capítulo, el cual no cabe duda pasará a formar parte del marco conceptual que dirige su acción.

El capítulo, A vida no espaço, es una posrreflexión que cierra y resume los conceptos vertidos de esta segunda parte poniendo al hombre y a sus obras en el lugar que le corresponde dentro de la problemática del tiempo y del espacio. Resulta interesante el enfoque que aquí se propone en materia de la subjetividad.

La tercera parte, titulada Vivendo em tempos espaciais?, presenta las comprensiones práctico-populares y teórico sociales de la autora con respecto al espacio, que parte desde el paradigma de la globalización como proceso de reestructuración del capitalismo tardío. Massey propone alternativas que abordan los vacíos detallados en las secciones previas, especialmente en la Segunda Parte. La Tercera Parte consiste en el desarrollo de tesis que pretenden empoderar a la geografía como posibilidad de especulación acerca de los contenidos de las visiones modernas de tiempo y espacio, que se complementan con los contenidos de la Cuarta y Quinta parte. Destacan las relaciones que la autora establece con la evolución del capitalismo y con los procesos que le acompañan en materia de deformación de la realidad. Urge, en virtud de la radicalidad de los cambios acontecidos en este último tiempo, elaborar una teoría que sitúe en su verdadera magnitud al espacio como continente-contenido, totalidad transformada, también en transformación y agente de cambio de los elementos que lo constituyen.

La obra aquí reseñada debe ser considerada como un texto de consulta para aque-
Ilos que deseen profundizar sus conocimientos en materia del camino epistemológicoconceptual que ha marcado la evolución de la geografía humana como un todo y de la geografía cultural a partir del giro de los ochenta.

Por último, puede ser que Pelo Espaço, en el mediano y largo plazo, constituya un insumo para quienes emprendan el desafío de situar a la ciencia geográfica como un aporte al desarrollo de las humanidades y de las ciencias sociales desde el siglo pasado hasta nuestros días.

\section{Consideraciones finales}

Resulta especialmente notable el ímpetu de la geografía en Brasil. Esto se refleja en los agradecimientos y/o prefacio del texto y en la simultaneidad con la cual este libro ha sido traducido al portugués en circunstancias que aún no hay versión en español.

A propósito de una reflexión acerca del objeto de estudio de la geografía, se pasa revista a una serie de problemáticas de carácter metodológico que han incidido en el desarrollo de la evolución teórica de la geografía.

Además, se hace una exhaustiva revisión de los modos como los giros epistemológicos de las ciencias han afectado y en muchas ocasiones han obnubilado a los geógrafos, ocasionando, en algunos casos, un grave daño y un retroceso al desarrollo teórico de las ciencias.

Finalmente, se debe mencionar que toda reflexión tiene un locus; surge y se justifica en un contexto. A partir de la lectura del texto se pueden inferir las preocupaciones del mundo anglosajón y los giros que ha experimentado la geografía en el primer mundo en el último tiempo, replicados, en alguna medida, en Brasil, España y México. 